\title{
ÁREA FOLIAR E ALTURA DE IPECA SÃO ALTERADAS PELO SOMBREAMENTO
}

Fernanda Naiara Santos Ribeiro ${ }^{1}$ Cristina Moll Hüther ${ }^{2}$ Daniela Marques Correia ${ }^{3}$ Thelma de Barros Machado ${ }^{4}$ Carlos Rodrigues Pereira ${ }^{5}$

${ }^{1}$ Doutora em Plantas Medicinais, Aromática e Condimentar, pela Universidade Federal de Lavras, Lavras, MG, Brasil.

${ }^{2}$ Pós-Doutoranda do Programa de Pós-Graduação em Engenharia de Biossistemas, Universidade Federal Fluminense, Niterói, RJ, Brasil. cristinahuther@yahoo.com.br (autor para correspondência)*

${ }^{3}$ Graduação em Engenharia Agrícola e Ambiental, Universidade Federal Fluminense.

${ }^{4}$ Professora doutora da Universidade Federal Fluminense, Faculdade de Farmácia, Niterói, RJ, Brasil.

${ }^{5}$ Professor doutor da Universidade Federal Fluminense, Escola de Engenharia, Niterói, RJ, Brasil.

\section{Recebido em: 06/04/2019 - Aprovado em: 10/06/2019 - Publicado em: 30/06/2019 DOI: 10.18677/EnciBio_2019A18}

\begin{abstract}
RESUMO
A ipeca (Carapichea ipecacuanha) é uma planta medicinal de grande importância financeira devido aos seus princípios ativos presentes em suas raízes, mas há poucos estudos quanto ao seu crescimento e desenvolvimento. Por esse motivo, o presente trabalho tem como objetivo determinar o crescimento em diferentes níveis de sombreamento nas condições ambientais de Niterói-RJ. O período das análises compreendeu a transição das estações de primavera para verão (dezembro de 2014 e janeiro de 2015), envolvendo sombreamentos de 50, 70 e 90\% em solo arenoso. Foram avaliados os seguintes parâmetros: altura, diâmetro do colo, número de folhas, área foliar e temperatura do ar e do solo. Quanto aos parâmetros altura e diâmetro, inicialmente, não houve diferença significativa em relação aos sombreamentos, mas no mês de janeiro as plantas no sombreamento de $50 \%$ apresentaram maior crescimento da altura em relação aos demais sombreamentos, exibindo um acréscimo de $48 \%$ em comparação ao sombreamento de $70 \%$. Quanto área foliar, o sombreamento de $50 \%$ também se mostrou mais eficiente, cujas plantas tiveram $80 \%$ a mais de crescimento que as plantas do sombreamento de $90 \%$, no mês de dezembro, e cerca de $78 \%$ a mais no mês de janeiro. A avaliação de temperatura demonstrou que 0 isolamento térmico, em todos os três sombreamentos, permitiu uma menor variação de temperatura do solo. Para o crescimento e desenvolvimento das mudas de ipeca o sombreamento de $50 \%$, foi o mais indicado, preferencialmente com isolante térmico, para a diminuição da variação de temperatura, podendo variar com a sazonalidade local.
\end{abstract}

PALAVRAS-CHAVE: Crescimento; planta medicinal; temperatura. 


\title{
LEAF AREA AND HEIGHT OF IPECA ARE ALTERED BY SHADING
}

\begin{abstract}
The ipeca (Carapichea ipecacuanha) is a medicinal plant with a big financial importance due to its active principle residing in its root, but there is a lack of studies towards its growth and development. For that matter, the present study intends to determinate its growth in different levels of shading on ambient conditions in NiteroiRJ. The analysis period was between the spring and summer (December 2014 and January 2015) involving shadings of 50, 70 e 90 in sandy soil. The parameters analyzed where: height, diameter, number of leafs, leaf area, soil and atmosphere temperature. In regard of the height and diameter, initially, there were no significant changes between the values acquired in December, however, in January, the plants in the $50 \%$ shading showed higher growth compared to the others, growing $48 \%$ in comparison to the $70 \%$ shading. In the measuring of the leaf area, the $50 \%$ shading was also more efficient, the plants had $80 \%$ more growth than the $90 \%$ shading in December and, around $78 \%$ more in January. The measuring of soil temperature was able to determinate that, in all three shadings, the thermal insulation allows less temperature variations. For the growth and development of the ipeca seedlings, the $50 \%$ shading was more suitable, especially if provided with thermal insulation, decreasing temperature variations, which can vary with seasonality.
\end{abstract}

KEYWORDS : Growth; medicinal plant; temperature.

\section{INTRODUÇÃO}

Um dos fatores que influenciam no crescimento e desenvolvimento de plantas é a incidência de radiação solar, pois dependendo da espécie, a intensidade elevada pode causar estresse na planta (MARTINELLI ; MORAES, 2013; MARIJUAN; BOSH, 2014). Diversos fatores podem dificultar o desenvolvimento da planta, dentre estes fatores a luminosidade (FLORES; BRUCKNER, 2015) e a temperatura (PEREIRA et al., 2016). Cada espécie vegetal pode reagir de forma diferente à estresse, principalmente para plantas medicinais que podem demonstrar diferenças na produção de seus princípios ativos (PAVARINI et al., 2012). Uma forma de diminuir a ação de radiação direta nas plantas é o uso de sombreamento. Diferentes níveis de radiação acarretam em diferentes respostas fisiológicas (ARAGÃO et al., 2014).

A ipeca é uma planta medicinal de grande importância econômica (KORNPOINTNER et al., 2018), seu estudo é de grande relevância, pois contém em suas raízes, dois alcaloides de importância farmacêutica, a emetina e a cefalina. Estes são utilizados para tratamentos de diarreia e, além disso, tem propriedade expectorante, adstringente e anti-inflamatória (LAMEIRA, 2002; VIEGAS et al., 2014), dentre outras propriedades sendo ainda analisadas, como para o tratamento de malária (MATTHEWS et al., 2013) e na inibição de infecções causadas pelo vírus Zika e pelo Ebola (YANG et al., 2018).

Tendo em vista a importância dessa espécie e a escassez de estudos direcionados ao desenvolvimento da planta, se faz cada vez mais necessário expandir o conhecimento quanto ao crescimento da planta de acordo com determinados parâmetros considerados relevantes, como temperatura do solo e incidência de radiação na planta. Sendo assim, o presente trabalho tem como objetivo determinar o crescimento em diferentes níveis de sombreamento nas condições ambientais de Niterói-RJ. 


\section{MATERIAL E MÉTODOS}

O presente trabalho foi realizado no campus Gragoatá da Universidade Federal Fluminense, localizado em Niterói-RJ, em casas de vegetação, latitude $22^{\circ} 54^{\prime} 00^{\prime} \mathrm{S}$, longitude $43^{\circ} 08^{\prime} 00^{\prime \prime} \mathrm{W}$ e altitude de 8 metros com temperatura anual média de $23^{\circ} \mathrm{C}$. O material vegetal utilizado no trabalho foi obtido no Banco Ativo de Germoplasma de ipeca ex-situ, provenientes do Herbário da Embrapa Amazônia Oriental em Belém (PA), amostras da exsicata: IAN 194095 e IAN 194432. As raízes obtidas foram propagadas, conforme descrito por Ribeiro et al. (2017) e geraram as mudas que foram transplantadas para vasos de polietileno de 8 litros, contendo solo arenoso, caracterizado como distrófico, com saturação de alumínio de $37 \%$ e valores de $\mathrm{pH}$ em água de 5,3 . Não foi realizado o ajuste do $\mathrm{pH}$, devido às recomendações para essa espécie ser de 5,5 (LAMEIRA, 2002).

O experimento foi realizado no período de dezembro de 2014 e janeiro de 2015 , em três níveis distintos de sombreamento contendo tela do tipo sombrite ${ }^{\circledR}(50$, 70 e $90 \%)$, bem como o uso de "Isolante Térmico Alumínio Duralfoil ${ }^{\Theta}$ " (ITAD), para para impedir a incidência de radiação solar direta e para aumentar a aeração, todos os dias, entre $16 \mathrm{~h}$ e $9 \mathrm{~h}$ da manhã, as laterais do sombrite ${ }^{\circledR}$ e ITAD foram levantadas.

As plantas foram irrigadas diariamente, por meio de uma mangueira, visando manter o nível de umidade próximo à capacidade de campo e as avaliações foram realizadas semanalmente. Verificou-se a altura $(\mathrm{cm})$, diâmetro do caule $(\mathrm{mm})$, número de folhas e área foliar $\left(\mathrm{cm}^{2}\right)$.

Para mensuração da altura, foi utilizada a régua graduada, medindo-se da base da emissão de brotação até o início da inserção da última folha. Já para o diâmetro, foi utilizado o paquímetro que foi posicionado na base de emissão de brotação.

A determinação da área foliar foi feita por método direto, onde as medidas são feitas diretamente nas folhas, de modo não destrutivo (FLUMIGNAN et al., 2007). Realizaram-se também medidas de temperatura do solo, nos horários de 6, 12 e 18 horas, realizadas através de termômetros de solo.

O experimento foi inteiramente casualizado, com três níveis de sombreamento 50, 70 e 90\%, com 8 repetições, sendo que cada repetição era representada por 4 plantas, totalizando 96 plantas. Os dados coletados foram tabulados e submetidos aos testes de normalidade e homogeneidade, e as médias dos tratamentos comparadas pelo teste Tukey a $5 \%$ de probabilidade, utilizando o programa estatístico Assistat Software (SILVA; AZEVEDO, 2016).

\section{RESULTADOS E DISCUSSÃO:}

Os parâmetros de altura e diâmetro mostraram diferenças entre os níveis de sombreamento. Para o sombreamento de $90 \%$ foi observada uma média de $2,60 \mathrm{~cm}$ de altura e 1,63 mm de diâmetro. Entretanto, no sombreamento de $70 \%$, foi obtida uma média de $2,12 \mathrm{~cm}$ de altura e $1,40 \mathrm{~mm}$ de diâmetro. Destaca-se 0 sombreamento de $50 \% \mathrm{com}$ média de $4,66 \mathrm{~cm}$ de altura e $1,93 \mathrm{~mm}$ de diâmetro (Figura $1 \mathrm{~A}$ e B). 

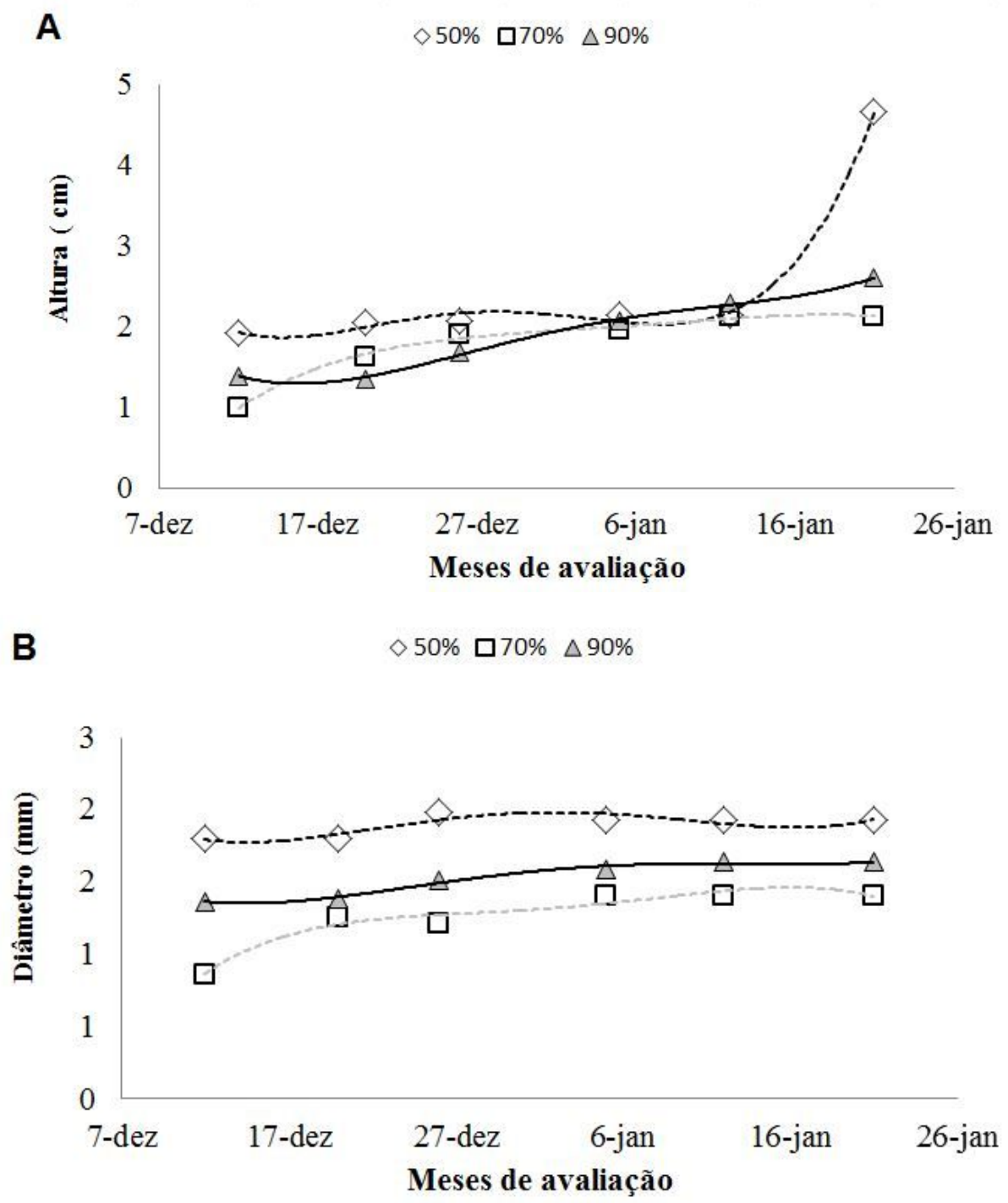

FIGURA 1. Médias da altura (cm) (A) e Médias do diâmetro (mm) (B) da ipeca em sombreamentos de 50,70 e $90 \%$ em solo arenoso, no período de dezembro de 2014 a janeiro de 2015. Fonte: autor.

As plantas utilizadas no experimento foram indivíduos em processo de crescimento, por isso os exemplares apresentaram inicialmente alturas diferentes. Com base na falta de material uniforme para realizar o transplantio, as plantas foram distribuídas aleatoriamente no experimento, uma vez que a espécie não tem uma propagação vegetativa uniforme, sendo difícil obter mudas padronizadas (RIBEIRO et al., 2017). Os fatores externos como salinidade do solo e temperatura contribuíram para que as plantas estivessem em uma condição subótima, fazendo com que valores de alguns parâmetros passassem por um decréscimo. Segundo Pavarini et al. (2012), devido à influência de fatores bióticos e abióticos, o metabolismo secundário da planta pode ser alterado, dependendo do tipo de estresse. Existe a possibilidade de aumento na produção dos princípios ativos em plantas medicinais (TAKSHAK; AGRAWAL, 2019; THAKUR et al., 2019).

Durante esse período as plantas não demonstraram crescimento visual, porém, as atividades metabólicas continuaram, embora com intensidade reduzida. Quando os indivíduos se aclimataram ao novo local, após o transplantio, 
encontrando um ambiente adequado, iniciou-se novamente 0 processo de crescimento. Como visto por Feller (2016) e Xiaolu et al. (2016), plantas sob estresse, podem recuperar suas condições iniciais, por completo ou parcialmente, dependendo do estresse e intensidade. Para o mesmo período também foram mensurados o número de folhas e a área foliar $\left(\mathrm{cm}^{2}\right)$, representada nas Figuras 2 (A e B).
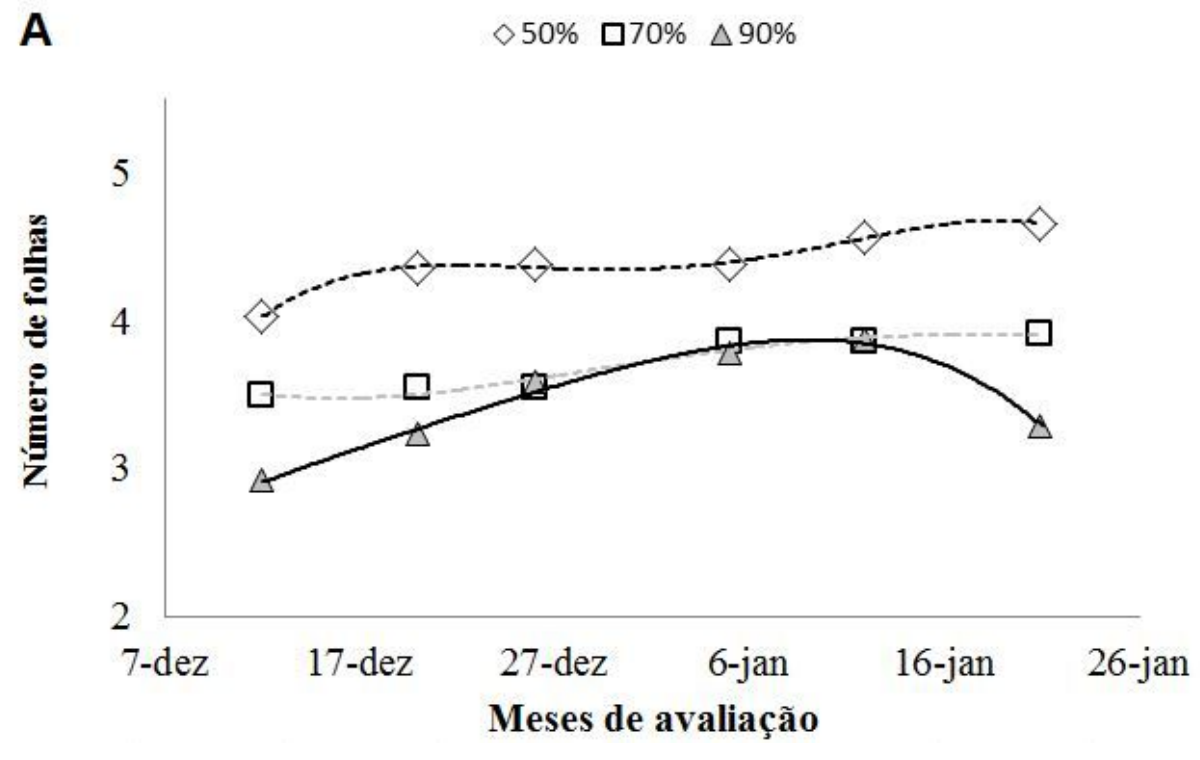

B $\quad \diamond 50 \% \square 70 \% \triangle 90 \%$

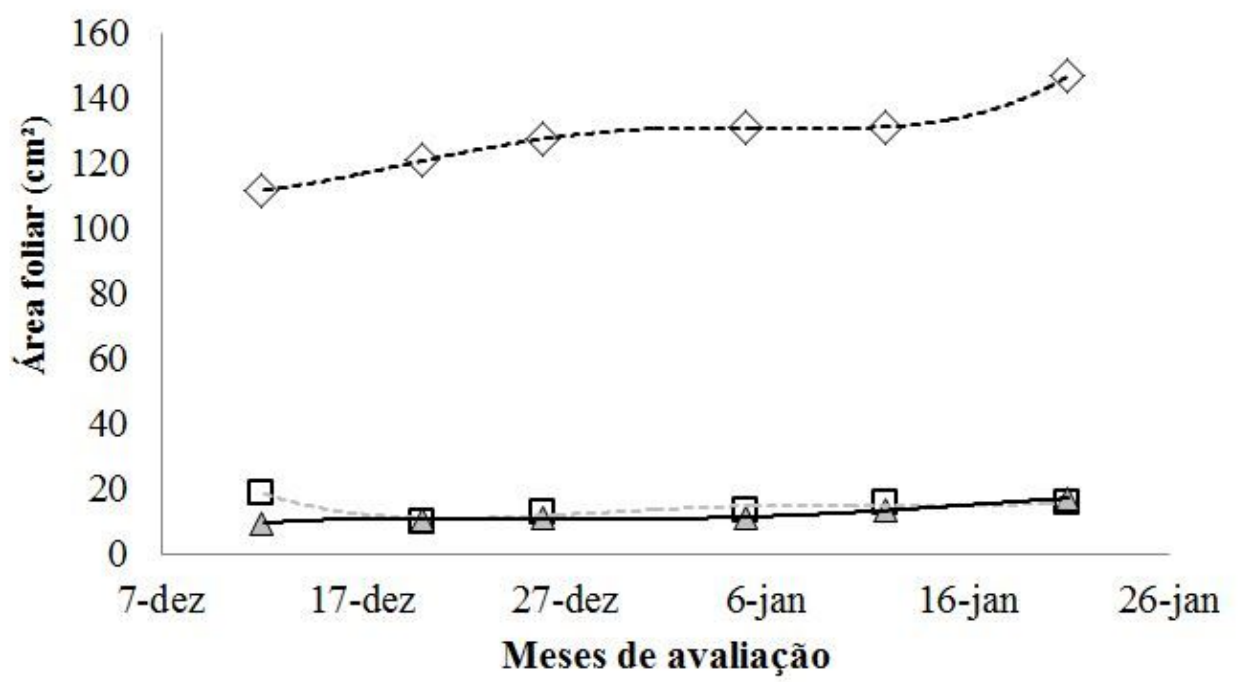

FIGURA 2. Média do número de folhas de ipeca em sombreamentos de 50,70 e $90 \%$ (A) e Média da área foliar $\left(\mathrm{cm}^{2}\right)$ de ipeca em sombreamentos de 50 , 70 e 90\%, ambas no período de dezembro de 2014 a janeiro de 2015 (B). Fonte: autor.

Com relação a estes parâmetros, pode-se observar que houve diferença entre os valores com destaque para o sombreamento de $50 \%$ que obteve média de 6 folhas e área foliar de $146 \mathrm{~cm}^{2}$. Para o sombreamento de $70 \%$ a média foi de 4 folhas e $15,68 \mathrm{~cm}^{2}$ de área foliar. No sombreamento de $90 \%$ a média de folhas foram 2 folhas e $17,07 \mathrm{~cm}^{2}$ de área foliar. 
A análise detalhada dos parâmetros de altura, diâmetro, número de folhas e área foliar, para dezembro de 2014 e janeiro de 2015, estão dispostos na Tabela 1.

TABELA 1. Relação dos parâmetros altura $(\mathrm{cm})$, número de folhas, diâmetro $(\mathrm{mm}) \mathrm{e}$ área foliar $\left(\mathrm{cm}^{2}\right)$ com os sombreamentos utilizados nos períodos de dezembro de 2014 e janeiro de 2015.

\begin{tabular}{|c|c|c|c|c|c|c|}
\hline & \multicolumn{3}{|c|}{ Dezembro (2014) } & \multicolumn{3}{|c|}{ Janeiro (2015) } \\
\hline Parâmetros & $90 \%$ & $70 \%$ & $50 \%$ & $90 \%$ & $70 \%$ & $50 \%$ \\
\hline Altura $(\mathrm{cm})$ & $2,29 a^{*}$ & $2,47 a$ & $2,65 a$ & $2,68 b$ & $2,60 \mathrm{~b}$ & $5,00 a$ \\
\hline Número de folhas & $3,18 \mathrm{a}$ & $3,54 \mathrm{a}$ & $4,07 \mathrm{a}$ & $3,28 a$ & $3,12 \mathrm{a}$ & $4,38 \mathrm{a}$ \\
\hline Diâmetro (mm) & $1,38 \mathrm{a}$ & $1,25 \mathrm{a}$ & $1,79 \mathrm{a}$ & $1,41 \mathrm{a}$ & $1,40 a$ & $1,97 \mathrm{a}$ \\
\hline Área Foliar $\left(\mathrm{cm}^{2}\right)$ & $9,12 \mathrm{~b}$ & $11,41 \mathrm{~b}$ & $47,50 \mathrm{a}$ & $14,46 \mathrm{~b}$ & $14,54 \mathrm{~b}$ & $64,42 \mathrm{a}$ \\
\hline
\end{tabular}

*As médias seguidas pela mesma letra minúscula na linha não diferem estatisticamente entre si pelo Teste de Tukey ao nível de 5\% de probabilidade. Níveis de sombreamento: 50, 70 e $90 \%$. Fonte: autor.

No mês de dezembro destacou-se o sombreamento de $50 \%$ que diferiu significativamente, mostrando-se mais eficiente, quanto à área foliar, com uma média de $47,50 \mathrm{~cm}^{2}$. Contudo, para os outros parâmetros, não houve diferença significativa, porém, numericamente, o sombreamento de $50 \%$ se destaca em relação aos sombreamentos de 70 e $90 \%$, obtendo média de 2,65 cm de altura, 4,07 folhas e $1,79 \mathrm{~mm}$ de diâmetro.

Para o mês de janeiro, tem-se uma diferença significativa nos parâmetros altura e área foliar para o sombreamento de $50 \%$, mostrando novamente melhor desempenho que os demais, com $5 \mathrm{~cm}$ de altura e $64,42 \mathrm{~cm}^{2}$ de área foliar. 0 número de folhas e diâmetro, para o sombreamento de $50 \%$ foram, respectivamente, 4,38 folhas e $1,97 \mathrm{~mm}$.

Em relação à temperatura do ar e à temperatura do solo, quando comparadas, observou-se que para os horários de 6, 12 e 18 horas nos sombreamentos de 50, 70 e 90\% (Figura 3A) apresentou pouca variação em relação aos sombreamentos, no entanto, variando mais entre os horários. Porém, analisando a temperatura do solo (Figura 3B), quando comparado essas casas de vegetação com sombreamentos contendo Isolante Térmico Alumínio Duralfoil $\circledast$ e outras contendo somente sombrites $\AA$, na mesma condição do experimento, ocorreu uma grande variação na temperatura do solo, pois a diferença de temperatura às 6 horas foi de $0,92^{\circ} \mathrm{C}$; às 12 horas, a diferença foi de $3,34^{\circ} \mathrm{C}$; às 18 horas, a diferença foi de $4,19^{\circ} \mathrm{C}$. Esse resultado ressalta a importância do isolamento térmico no cultivo da ipeca. 

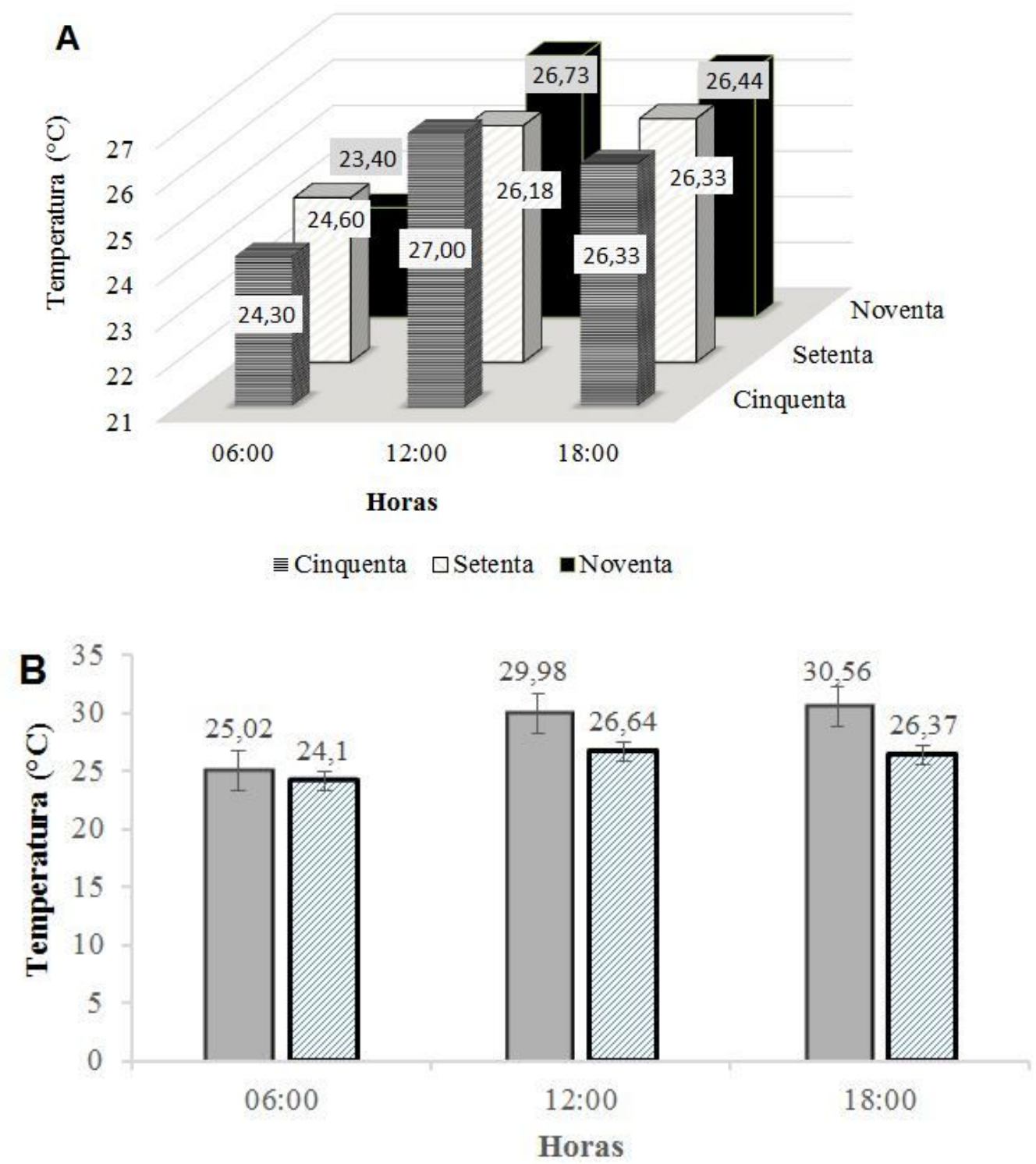

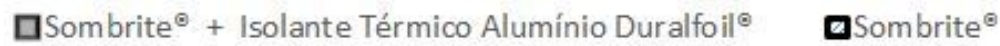

FIGURA 3- (A) Temperatura do ar nos sombreamentos de 50,70 e $90 \%$ e (B) temperaturas do solo no sombreamento controlado (Isolante Térmico Alumínio Duralfoil $(\mathrm{B}-\mathrm{ITAD})+$ sombrite $\AA$. Temperaturas para as 6, 12 e 18 horas no período de dezembro de 2014 a janeiro de 2015. Fonte: autor.

Segundo Pezzopane et al. (2004) fatores como local, época do ano, altitude e horário do dia podem alterar a radiação solar pela tela plástica, sendo assim, cada região e época do ano podem requerer tipos diferentes de tela para o cultivo de determinada espécie.

Dessa forma, para essas condições experimentais observou-se que para o crescimento mais acelerado em relação à área foliar e altura, o sombreamento de $50 \%$ se mostrou mais eficiente, o que poderá representar um melhor desenvolvimento da planta. No entanto, isso poderá ser alterado se for analisado a relação com a sazonalidade, pois o período em que compreendeu as análises foi a transição entre as estações primavera e verão. 


\section{CONCLUSÃO}

Nessas condições experimentais, o melhor resultado para o crescimento e desenvolvimento das mudas de ipeca é o sombreamento de $50 \%$, preferencialmente com isolante térmico, para a diminuição da variação de temperatura, tendo em vista seu habitat natural ser de sub-bosque.

\section{AGRADECIMENTOS:}

O presente trabalho foi realizado com apoio da Coordenação de Aperfeiçoamento de Pessoal de Nível Superior - Brasil (CAPES), da Empresa Brasileira de Pesquisa e Agropecuária - Embrapa Amazônia Oriental e da Fundação de Amparo à Pesquisa do Estado do Rio de Janeiro (FAPERJ).

\section{REFERÊNCIAS}

ARAGÃO, D. S.; LUNZ, A. M. P.; OLIVEIRA, L. C.; RAPOSO, A.; JUNIOR, P. C. P. F. Efeito do sombreamento na anatomia foliar de plantas jovens de andiroba (Carapa guianensis Aubl). Revista Árvore, v. 38, n. 4, p. 631-639, 2014. Disponível em: <http://dx.doi.org/10.1590/S0100-67622014000400006>. doi: 10.1590/S010067622014000400006

FELLER, U. Drought stress and carbono assimilation in a warning climate: Reversible and irreversible impacts. Jornal of Plant Physiology, 203, p. 84-94, 2016. Disponível em: < http://dx.doi.org/10.1016/j.jplph.2016.04.002>. doi: 10.1016/j.jplph.2016.04.002

FLORES, P. S.; BRUCKNER, C. H. Radiossensibilidade de sementes e segmentos caulinares de maracujazeiro-amarelo submetidos a radiação gama. Ciência Rural, v. $45, \quad$ n. 12, p. 2131-2136 2015. Disponível em: <http://dx.doiorg.ez24.periodicos.capes.gov.br/10.1590/0103-8478cr20121274>. doi: $10.1590 / 0103-8478 \mathrm{cr} 20121274$

FLUMIGNAN, D. L.; ADAMI, M.; FARIA, R. T. Área foliar de folhas íntegras e danificadas de cafeeiro determinada por dimensões foliares e imagem digital. Coffee

Science, v. 3, n. 1, p. 1-6, 2008. Disponível em: < http://www.coffeescience.ufla.br/index.php/Coffeescience/article/view/791>. doi: 10.25186/cs.v3i1.67.

KORNPOINTNER, C.; BERGER, A.; FISCHER, I. M.; POPL, L.; GROHER, C.; VALANT-VETESCHERA, K.; BECKER, L.; SCHINNERL, J. Revisiting Costa Rican Carapichea affinis (Rubiaceae: Palicoureeae): A source of bioactive dopamine-iridoid alkaloids. Phytochemistry Letters, v. 26, p. 164-169, 2018. Disponível em: < https://app.dimensions.ai/details/publication/pub.1104556923?and_facet_journal=jou r.1297153>. doi: 10.1016/j.phytol.2018.05.004

LAMEIRA, O. A. Cultivo da Ipecacuanha [Psychotria ipecacuanha (Brot.) Stokes]. Circular técnica, 28, p. 1-4, 2002. Disponível em: $<$ https://www.infoteca.cnptia.embrapa.br/bitstream/doc/405771/1/Circ.tec.28.pdf>. MARTINELLI, G.; MORAES, M. A. Livro vermelho da flora do Brasil. Jardim Botânico do Rio de Janeiro, p.1-1102, 2018. Disponível em: $<$ http://dspace.jbrj.gov.br/jspui/handle/doc/92>. 
MATTHEWS, H.; USMAN-IDRIS, M.; KHAN, F.; READ, M.; NIRMALAN, N.; Drug repositioning as a route to anti-malarial drug discovery: preliminary investigation of the in vitro anti-malarial efficacy of emetine dihydrochloride hydrate. Malaria Journal, v.12, n. 359, p.1-11, 2013. Disponível em: < https://malariajournal.biomedcentral.com/articles/10.1186/1475-2875-12-359>. doi: https://doi.org/10.1186/1475-2875-12-359.

PAVARINI, D. P.; PAVARINI, S. P.; NIEHUES, M.; LOPES, N. P. Exogenous influences on plant secondary metabolite levels. Animal Feed Science and Technology, v. 176, n. 1-4, p. 5-16, 2012. Disponível em: < https://pdf.sciencedirectassets.com/271182/1-s2.0-S0377840112X00117/1-s2.0S0377840112002350/dx.doi.org/10.1016/j.anifeedsci.2012.07.002 >. doi: 10.1016/j.anifeedsci.2012.07.002

PEREIRA, F. E. C. B.; FILHO, S. M.; TORRES, S. B.; MARTINS, C. C.; BRITO, S. F. Saline stress and temperatures on germination and vigor of Piptadenia moniliformis Benth. seeds. Revista Brasileira de Engenharia Agricola e Ambiental, vol. $20 \mathrm{n}$. 7, p. 649-653, 2016. Disponível em: <http://dx.doiorg.ez24.periodicos.capes.gov.br/10.1590/1807-1929/agriambi.v20n7p649-653>. doi: 10.1590/1807-1929/agriambi.v20n7p649-653

PEZZOPANE, C. G.; FAVARIN, J. L.; MALUF, M. P.; PEZZOPANE, J. R. M.; FILHO, O. G. Atributos fenológicos e agronômicos em cultivares de cafeeiro arábica. Ciência Rural, v. 39, n. 3, p. 711-717, 2008. Disponível em: <http://dx.doi.org/10.1590/S0103-84782009005000007>. doi: 10.1590/S010384782009005000007

PINTÓ-MARIJUAN, M.; MUNNÉ-BOSCH S. Photo-oxidative stress markers as a measure of abiotic stress -induced leaf senescence: advantages and limitations. Journal of Experimental Botany, v. 65, n. 14, p. 3845-3857, 2014. Disponível em: $<\quad$ https://doi-org.ez24.periodicos.capes.gov.br/10.1093/jxb/eru086>. doi: 10.1093/jxb/eru086

RIBEIRO, F. N. S.; HÜTHER C. M.; MACHADO T. B.; LAMEIRA O. A.; PEREIRA C. $R$. Propagação de ipecacuanha por estacas de raiz em diferentes condições ambientais e substratos. Enciclopédia Biosfera, v. 14, n. 25, p. 1072-1083, 2017. Disponível em: < https://www.embrapa.br/busca-de-publicacoes//publicacao/1072035/propagacao-de-ipecacuanha-por-estacas-de-raiz-emdiferentes-condicoes-ambientais-e-substratos>. doi: 10.18677/EnciBio_2017A86

SILVA, F. A. S.; AZEVEDO, C. A. V. The Assistat Software Version 7.7 and its use in the analysis of experimental data. African Journal of Agricultural Research, v. 11, n. 39, p. 3733-3740, 2016. Disponível em: < https://academicjournals.org/journal/AJAR/article-full-text-pdf/5E8596460818>. https://doi.org/10.5897/AJAR2016.11522.

TAKSHAK, S.; AGRAWAL, S. B. Defense potential of secondary metabolites in medicinal plants under UV-B stress. Journal of Photochemistry and Photobiology, B: Biology, v. 193, p. 51-88, 2019. Disponível em: 
$<$ https://doi.org/10.1016/j.jphotobiol.2019.02.002>.

doi:

10.1016/j.jphotobiol.2019.02.002

THAKUR, M.; BHATTACHARYA, S.; KHOSLA, P. K.; PURI, S. Improving production of plant secondary metabolites through biotic and abiotic elicitation. Journal of Applied Research on Medicinal and Aromatic Plants, v. 12, p. 1-12, 2019. Disponível em: < https://doi.org/10.1016/j.jarmap.2018.11.004>. doi: 10.1016/j.jarmap.2018.11.004

VIEGAS, I. J. M.; GALVÃO, J. R.; JÚNIOR, M. L. S.; MELO N. C.; OLIVEIRA, M. S. Crescimento, composição mineral e sintomas visuais de deficiência nutricional em ipeca. Revista Caatinga, v. 27, p.141-147, 2014. Disponível em: <

www.nutricaodeplantas.agr.br/site/downloads/unesp jaboticabal/omissao ipeca1.pdf

XIAOLU, W.; JIE Y.; AOXUE L.; YU C.; YIJUN F. Drought stress and re-watering increase secondary metabolites and enzyme activity in dendrobium moniliforme. Industrial Crops \& Products, v. 94, p. 385-393, 2016. Disponível em: < https://pdf.sciencedirectassets.com/271144/1-s2.0-S0926669016X0012X/1-s2.0S0926669016305544/dx.doi.org/10.1016/j.indcrop.2016.08.041>. doi: 10.1016/j.indcrop.2016.08.041

YANG, S.; XU, M.; LEE, E.M.; GORSHKOV, K; SHIRYAEV, S.A.; SHIHUA, H.; SUN, W.; et al., Emetine inhibits Zika and Ebola virus infections through two molecular mechanisms: inhibiting viral replication and decreasing viral entry. Cell Discovery 4, n. 31, p. 4IS-1AB, 2018. Disponível em: < https://doi.org/10.1038/s41421-018-00341>. doi: $10.1038 / \mathrm{s} 41421-018-0034-1$ 